\title{
Editorial
}

\section{History in the public health tool kit}

The public health tool kit has expanded in recent years. For much of the period since the second world war, epidemiology has been its technical tool par excellence. But recently the role of epidemiology has been questioned, and its shortcomings have been highlighted. Epidemiologists have been establishing scientific alliances with other disciplines; the rise of genetics within public health is the most prominent example. The connections with social science have a long history and go back to the emergence of a separate medical sociology in the postwar years. ${ }^{1}$

History, too, is emergent as part of the public health tool kit. However, as Perdiguero and his colleagues remind us in this issue (see page 667), this is a re-emergence rather than a totally new development. In the 18 th and 19 th centuries there were mutual relations between history and epidemiology. At my own institution in the interwar years, the leading epidemiologist Major Greenwood taught both history and epidemiology to the students. Since then history has retained a foothold in public health, and tends to be used in two main ways. There is the "great man" school of history that looks to the past for inspiration. Edwin Chadwick or John Snow and their battle with disease provide a model for the present, for the developing countries' need for clean water and sanitation or the growing environmental emphasis within "new public health". And there is the strong historical quantitative tradition, through time series of mortality or historical epidemiological research on the early life origins of adult disease.

This is fine; but is it enough? Perdiguero and his coauthors think not, and I would agree with them. They draw attention to the potential input from historians in providing long term and contextual perspectives on current health issues, in giving a critical perspective on the wider significance and impact of health interventions. To do this we need to re-shape the image of history in public health. How can we do it? I would suggest four issues to think about, which together could take history and public health into new areas.

Issue one would be dropping the idea that history is only the distant past. History is all around us. Both public health professionals and historians themselves are only just beginning to wake up to the idea that the past 50 or so years are history too. ${ }^{2}$ Public health, both as an ideology or concept, and as a set of organisational practices, has undergone enormous change in that period. ${ }^{3}$ Just think of the rise and reformulation of the "new public health" since the 1970s at both national and international levels. Yet little so has so far been published by historians on these developments and the analysis tends to be sociological and time unaware.

Issue two would be dropping the idea that historical research is just a matter of those "dusty archives". The data sources and the methodologies are broader than that. Not all archives are dusty and they are all around us and often in need of preservation. Public health professionals are sitting on a lifetime of historical material that needs proper deposit and archival attention. There are also other historical methodologies; and oral history is one of them. Its role in relation to health and welfare is a developing field. ${ }^{4}$ The life history interview holds strong sway, but there are other ways in which oral history can be used, as "policy ethnography", for example, as one commentator called it, "slow journalism". ${ }^{5}$ Some have begun to adapt social science oral methods like the focus group for drawing out historical reminiscence of sensitive topics such as sexual relationships.

Issue three is related to this methodology and concerns the location of history. The authors writing in this issue speak of their close collaboration with public health researchers. There are indeed a small band of historians in several countries, the UK, US, Australia for example, who work within health institutions rather than in disciplinary settings. Such historians are ideally placed to carry out the sort of historical ethnography to which I am referring; history is indeed all around them. But the location requires a complex balancing act, a need to avoid being taken over by the concerns of the present day and to retain a disciplinary perspective. Non-historians tend to use historical material in a different sort of way. A historian using tobacco industry archives for evidence of research developments, for example, would seek to place those developments in the context of the time they took place, rather than making a current "activist" point.

And this is related to my issue four, which is the need for clarity within public health on what historical outputs are likely to be. There is a danger that public health expects what history cannot deliver. Critical analysis is the essence of historical work. A historian colleague working in a UK health institution recently told me that his historical analysis was seen as undermining of the public health enterprise. His fellow researchers hoped for historical outputs that justified their efforts, rather than subjecting them to scrutiny. But serious historians will not use history to massage current preconceptions or to find historical justification for policy agendas. They should be there to explain and to contextualise. Let me give you an example. Historians would relate the recent rise of enthusiasm for genetic influences within public health to a pre history, to a similar alliance in the late 19th century, or indeed, to more recent interrelations that date back to the roots of new public health. ${ }^{6}$ Thomas McKeown was strongly interested in genetics; so, too, was Robert Platt, who as President of the Royal College of Physicians also encouraged the adoption of smoking as a public health issue. Preventive and genetic interests were interconnected even at a time when we think of genetics as absent from public health. Here is not something essentially new, as much commentary assumes, but carrying with it a history and a set of influences that need to be teased out and that may well be of significance in understanding the present.

There is much historical work that could be drawn on in this sort of way: the history of responses to old age provides another example. ${ }^{7}$ Is public health prepared to take on the 
analytical role of history? If so, my list of issues could provide a set of guidelines for the public health toolkit: and the future relationships could be exciting for both sides.

VIRGINIA BERRIDGE

Department of Public Health and Policy, Health Promotion Research Unit, London School of Hygiene and Tropical Medicine, Keppel Street, London WC1E 7HT, UK (virginia.berridge@lshtm.ac.uk)

1 Porter D, ed. Social medicine and medical sociology in the twentieth century. Amsterdam: Rodopi, 1997.
2 Cooter R, Pickstone J, eds. Medicine in the twentieth century. Amsterdam: Cooter R, Pickstone J, eds. Medicine

3 Donaldson RJ. Off the cuff. Reminiscences of my half century career in public health. Richmond: Murray Print, 2000. health. Richmond: Murray Print, 2000.
4 Bornat J, Porks R, Thompson P, et al. Oral history, health and welfare.

London: Routledge, 1999.

5 Berridge V. AIDS in the UK. The making of policy, 1981-1994. Oxford: Oxford University Press, 1996.

6 Coventry P, Pickstone J. From what and why did genetics emerge as a medical specialism in the 1970s in the UK? A case history of research, policy and services in the Manchester region of the NHS. Soc Sci Med 1999;49:122738

7 Thane P. Old age in English history. Past experiences, present issues. Oxford: Oxford University Press, 2000.

\section{Speaker's corner}

\section{Vision of a rapid, flexible, cost effective, survey-based public health surveillance system}

In 1999 a pilot project was conducted in the Durham health region (population of 500 000) in Canada, to test the concept and a prototype of a rapid risk factor surveillance system. This project was initiated because some health regions (there are 136 health regions across Canada) felt the need to have a rapid and flexible information system to supplement the data from national health surveys. National health surveys cannot always be directed towards local needs, usually have a limited number of questions, have a delay in publishing results, and are rather infrequent.

The highly successful pilot project produced monthly data made available at the end of each month. It also permitted monthly changes in the questions and inclusion of questions not normally included in national health surveys. Based on the experience of the pilot project, we have the following vision of a rapid, flexible, cost effective, survey-based public health surveillance system.

Firstly, a franchise model. Health regions that subscribe to the system will provide funds for data collection in the respective health regions. Provincial and federal health agencies will contribute funds for central support and system development. Contractors will conduct telephone interview of 100 randomly selected people per month per health region. Thus if fully implemented, this will produce a national sample of 163200 interviews per year in Canada.

Secondly, a turnkey package. Subscribers will get a comprehensive package that is completely ready for operation, from system design, data analysis, result interpretation to report writing. Health regions can "click and drag" to create their own questionnaire in any month from an inventory of standard questions, as governed by certain ground rules. Automated statistical packages will be provided for data analysis. Geographic information system (GIS) capabilities will be developed.

Thirdly, a global support system. To ensure that subscribers can use the system with comfort, there is help desk access to provide assistance, through a web site and a 24 hour toll free number. As in the OnStar system now available in some cars by which advisors can provide a car user with road maps and step by step global positioning, or send remote signals to unlock car doors when keys are locked inside, statistical advisors will provide guidance and help to users.

Routine national health surveys have not always been developed for the purpose of health surveillance. The feasibility of using ongoing sample surveys to supplement national health surveys needs to be further investigated.

BERNARD C K CHOI

Population and Public Health Branch, Health Canada, AL no 1918C3, Tunney's Pasture, Ottawva, Ontario K1A 0K9, Canada; Department of Public Health Sciences, University of Toronto; Department of

Epidemiology and Community Medicine, University of Ottawa, Canada

Population and Public Health Branch, Health Canada

D MOWAT

Correspondence to: Dr Choi (Bernard_Choi@hc-sc.gc.ca) 